\title{
Modeling of Actuator and Position Sensors for Attraction Type Magnetic Levitation System
}

\author{
Mrunal Deshpande, Member IEEE \\ Department of EEE, SSN College of \\ Engineering, Kalavakkam-603 110, \\ Kanchipuram Dt, TN. India
}

\author{
Dr. B. L. Mathur \\ Department of EEE, SSN College Of \\ Engineering, Kalavakkam-603 110, \\ Kanchipuram Dt, TN. India
}

\begin{abstract}
In electromagnetic attraction type of magnetic levitation system, the intensity of the force of attraction depends on the magnitude of the current through the coil. The coil hence must be designed in such a way that it does not get heated while producing the required force. Here Finite element analysis (FEA) is done to find the force produced on the object for a particular current. The position of the object to be levitated is detected by implementing optical sensors. With the change in the position, the output of the sensor varies which in turn alters the current flow through the coil. Here a lab built electromagnet is used to suspend an iron ball. Generally used screw gauge system for modeling of actuator characteristics and to know the distance between the object and coil is replaced by travelling microscope to obtain more accurate results. Commonly used pair of sensors is replaced here by an array of receivers. The array gives wide control range. Also a small permanent magnet is attached to the suspended object to reduce the current magnitude through the coil required to suspend the ball. The sensor output with respect to position is obtained experimentally and plotted. A robust controller is also designed for the system. The simulation results are presented for the same.
\end{abstract}

Keywords

Magnetic levitation, Travelling microscope, Array of sensors, Robust controller.

\section{INTRODUCTION}

In magnetic levitation system the suspended object does not make contact with any other object in the system. Hence this technique can be used to overcome friction and attain high speeds. It is gaining more and more popularity in medical field, frictionless bearings, clean room etc. But as the system is nonlinear, open loop and unstable, proper controller must be designed. Voltage control feedback linearization [1], [2],[3] Hळ [4], and many more control techniques have been reported. Prior to the controllers the actuator and sensors need to be modeled to obtain initial results accurately. In this paper an actuator and optical sensors are modeled. Generally only a pair of optical sensors is used [5], [6]. But here an array of sensors is used to increase the range of sensing the position of the moving object. The distance between the two consecutive positions of the object is too small. To avoid human errors, a travelling microscope is used to accurately note the position of the object (an iron ball) from the electromagnet.
Moreover it is noted that current flow through the coil for longer time heats the core. To reduce the current requirement and heating of the core a small permanent magnet is attached to the ball. For the designed coil FEA is carried out to obtain the variation in force and inductance with respect to distance. Only vertical single axis movement of the object is considered.

\section{ACTUATOR MODELING}

The object to be suspended is a ball weighing $0.0225 \mathrm{~kg}$. Finite element analysis is carried out to find the force acting on the ball at various distances. The turns are chosen such that the current required does not heat the coil immediately and produce the required force. Saturation is neglected as current required to lift the ball is too small. For constant current at various positions the corresponding force and flux linkage for the ball are noted. The electrical equation for the coil with applied voltage $\mathrm{V}$ volts is represented as:

$$
V=i R+\frac{d L(y) i}{d t}
$$

The inductance profile obtained is shown in 'Figure 1'.

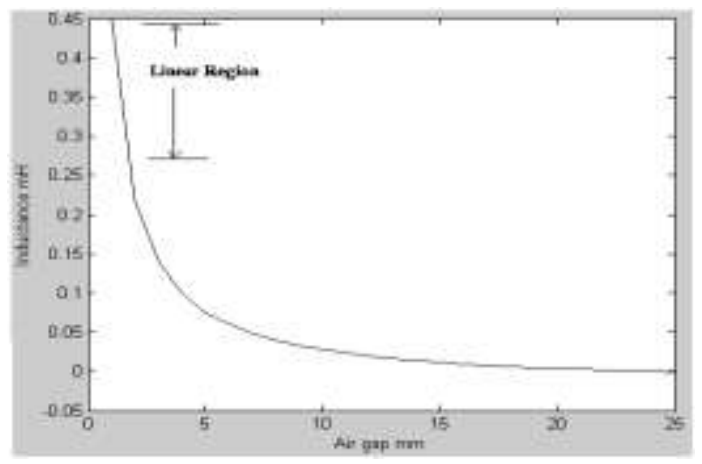

Figure 1 Variation of inductance of coil with respect to air gap

It can be noted from Fig (1) that as the ball moves near to the coil, the inductance of the coil increases. The equation for the inductance is as follows:

$$
L=\frac{\mu_{0} N^{2} A}{y}
$$


As the inductance of the lifting magnet is a function of the proximity of the levitated object, its inductance can be exploited for determination of the separation $y$.

$$
\mathbf{L}+\Delta \mathbf{L}=\frac{\boldsymbol{\mu}_{\mathbf{0}} \mathbf{N}^{2} \mathbf{A}}{\mathbf{y}+\Delta \mathbf{y}}
$$

If $\Delta \mathrm{y}$ is very small as compared to $\mathrm{y}$, then

$$
\Delta L=-\left(\frac{\mu_{0} N^{2} \mathbf{A}}{\mathbf{y}^{2}}\right) \Delta y
$$

A realistic mathematical model which includes all different aspects of the system behavior is needed to give a better knowledge in constructing a Maglev system. The total force produced on the object is

$$
\mathbf{F}=\mathbf{m g}-\mathbf{F}_{\mathbf{e}}
$$

$\mathrm{m}=$ mass of the object, $\mathrm{g}=$ acceleration due to gravity $=9.81$, $\mathrm{F}_{\mathrm{e}}=$ force due to the electromagnet. For a flow of current $\mathrm{i}$ in the coil of the electromagnet, the upward force of attraction produced by the magnet is

$$
F_{e}=\frac{1}{2}\left(\mu_{0} N^{2} A\right)\left(\frac{i}{y}\right)^{2}
$$

where $\mu_{0}$-permeability of free space, $\mathrm{N}$-number of turns, A-area of electromagnet. As downward force produced by gravity is $\mathrm{mg}$, the net force on the levitated object is given by

$$
m\left(\frac{d^{2} y}{d t^{2}}\right)-\frac{1}{2}\left(\mu_{0} N^{2} A\right)\left(\frac{i}{y}\right)^{2}+m g
$$

This is a non-linear equation that can be converted into small perturbation linear equation by neglecting second and higher order terms.

$$
\left(\frac{\mathrm{d}^{2} \Delta \mathrm{y}}{\mathrm{dt}^{2}}\right)=-\left(\frac{\mu_{0} \mathrm{~N}^{2} \mathrm{Ai}}{\mathrm{my}^{2}}\right) \Delta \mathrm{i}+\left(\frac{\mu_{0} \mathrm{~N}^{2} \mathrm{Ai}^{2}}{\mathrm{my}^{3}}\right) \Delta \mathrm{y}
$$

$$
=-\boldsymbol{k}_{1} \Delta_{i}+\boldsymbol{k}_{2} \Delta_{y}
$$

In Laplace domain, the transfer function

$$
\mathbf{G}(\mathbf{s})=\frac{\Delta \mathbf{y}(\mathbf{s})}{\Delta \mathbf{i}(\mathbf{s})}-\frac{\mathbf{k}_{\mathbf{1}}}{\mathbf{s}^{2}-\mathbf{k}_{\mathbf{2}}}
$$

Where $\mathrm{K}_{1}=0.882$ and $\mathrm{K}_{2}=147$. This clearly shows that the system is unstable. To make the system stable a feedback signal is required. A robust controller is hence developed. The object comes to a steady position with proper controller when gravitational force and attraction force are equal and opposite. Experimentally the current through the coil is varied at different positions of the object such that the current is just enough to bring balance between generated magnetic force and gravitational force. The plot of current versus distance is shown in 'Figure 2'. With curve fitting the equation for distance is modified as

$y=0.4454-0.0109 x+0.0019 x^{2}$

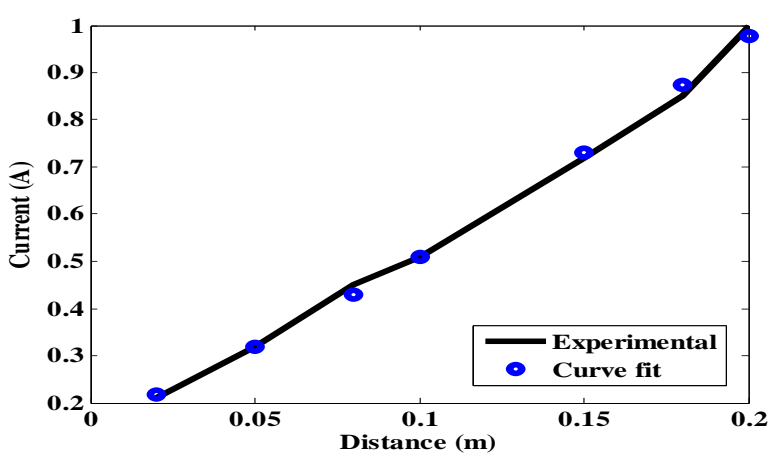

Figure 2 Current versus Distance

\section{SENSOR MODELING}

To know the exact position of the suspended object optical sensors are used. The output of the sensors is proportional to the position of the object. If only one sensor is used the change in the output is limited and is for very small distance variation. Hence here five receivers' are used to extend the range of sensing the position. The arrangement is as in 'Figure 3'.

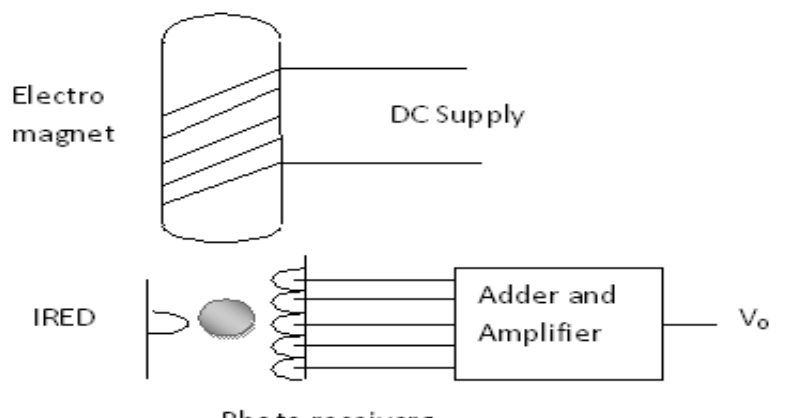

Pho to receivers

Figure 3 Sensor arrangement 
As the difference between the two consecutive positions of the ball is very small, to obtain accurate results a travelling microscope shown in Fig (4) is used to note the exact position.

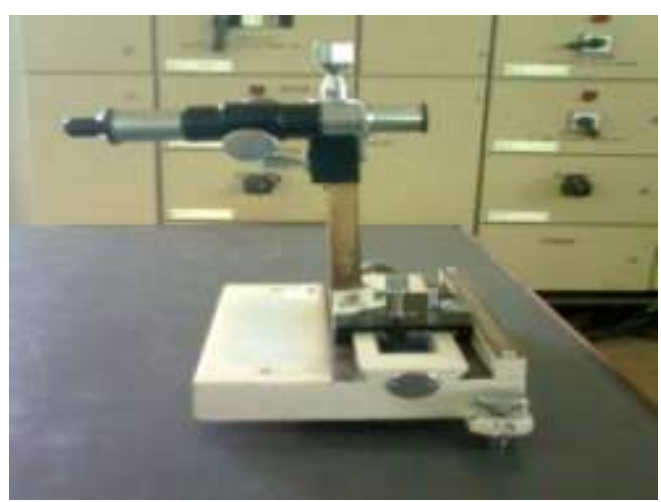

Figure 4 Travelling Microscope

The output of five receivers is added and amplified. The variation in output voltage of the sensor with respect to movement of the ball is plotted in Fig (5). It can be seen

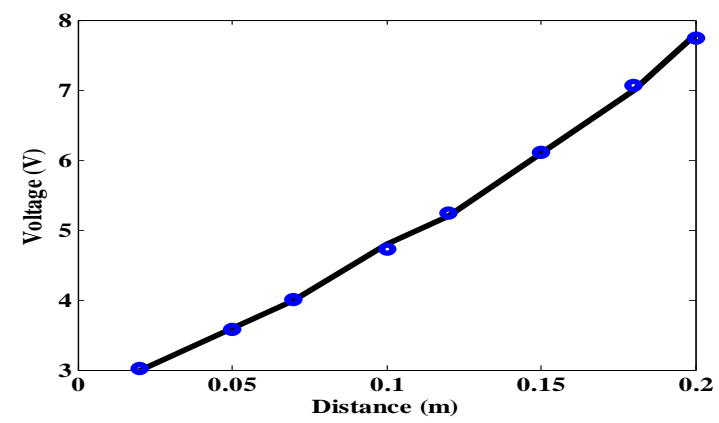

Figure 5 Voltage versus Distance

that as the ball moves away from the magnet the sensor output increases as less number of sensors are blocked by the ball. Though the sensors are assumed to be identical their characteristics differ. Moreover though the sensors are placed very close to each other, the minute gap between them affects the output which is noted in the plot but cannot be avoided. Hall Effect sensors are also used as position sensors. But these were found to be too delicate to solder and difficult to mount. They are to be mounted near to the core and get damaged easily if the object strikes the sensor when fully attracted by the core. Optical sensors comparatively are easy to mount and are cheaper than the Hall- effect sensors.

\section{THE CONTROLLER}

From equations (1), (3) and (7) the state space model of magnetic levitation system can be represented as

$$
\frac{d y_{1}}{d t}=x_{2}
$$

$$
\begin{gathered}
\frac{d x_{2}}{d t}=g_{a}-\frac{c}{m} \frac{i^{2}}{\left(a+y_{1}\right)^{2}}=x_{3} \\
\dot{x}_{3}=f(x)+g(y) u
\end{gathered}
$$

$$
\frac{d i}{d t}=\frac{i R}{L}+\frac{2 C}{L}\left(\frac{i^{2}}{\left(a+y_{1}\right)^{2}}\right)+\frac{u}{L}
$$

Where $\mathrm{y} 1=$ displacement, $\mathrm{x}_{2}=$ velocity, $x_{3}=$ acceleration. $\mathrm{u}=$ control voltage. At equilibrium the acceleration $\mathrm{x} 3$ is zero and current is:

$$
\mathbf{i}=\left(\mathbf{a}+\mathbf{y}_{\mathbf{1}}\right) \sqrt{\frac{\mathbf{g}_{\mathbf{a}} \mathbf{m}}{\mathbf{C}}}
$$

This gives the dynamic model of the system. The above equations are implemented to design sliding mode controller in the next section.

\subsection{Sliding Mode Controller}

Sliding mode controller (SMC) [7], [8], [9] and [10] tolerates the non-linearities and uncertainties and hence the developed system is made robust by implementing SMC. The first step in the design of sliding mode controller is the design of switching surface $S(y)$ $=0$ to represent a desired system dynamics which is of lower order than the given plant. The next step is to design a suitable control law, such that any state of the system outside the switching surface is driven to reach the surface in finite time.

The switching surface denoted by S can be represented by:

$$
S=x_{3}+\gamma_{1} x_{2}+\gamma_{2}\left(y-y_{1 d}\right)
$$

Where $\mathrm{x}_{1 \mathrm{~d}}$ is the desired reference value of $\mathrm{x}_{1}$ and $\gamma_{1} \& \gamma_{2}$ are positive scalars chosen such so that $s^{2}+\gamma_{1} s+\gamma_{2}$ is a Hurwitz polynomial. As $\boldsymbol{t} \rightarrow \infty \boldsymbol{e r r o r}\left(\boldsymbol{y}-\boldsymbol{y}_{1 \boldsymbol{d}} \rightarrow \mathbf{0}\right.$ and sliding surface $S \rightarrow 0$. With this switching surface designed, the reaching phase equation is to be developed. The control law equation is sum of steady state and transient equation where the steady state equation represents the reaching state and the other part includes the signum function which can be modified to reduce chattering. Using equation (13), the control equation is obtained as follows:

$\mathbf{u}=\frac{1}{g}\left(-f-\gamma_{1} x_{3}-\gamma_{2} x_{2}\right)-\frac{w}{g} \operatorname{sign}(S)$ 
or

$$
\mathbf{u}=\mathbf{u}_{\mathbf{1}}-\mathbf{u}_{\mathbf{2}}
$$

\section{SIMULATION RESULTS}

The values of the parameters of the plant and controller are given in Table 1

Table 1 Parameter values

\begin{tabular}{|c|c|c|c|l|l|}
\hline $\begin{array}{c}\text { Para- } \\
\text { meters }\end{array}$ & Value & $\begin{array}{c}\text { Para- } \\
\text { meters }\end{array}$ & Value & $\begin{array}{c}\text { Para- } \\
\text { metes }\end{array}$ & Value \\
\hline $\mathrm{C}$ & $7.9 * 10^{5}$ & $\mathrm{~L}$ & $0.1793 \mathrm{H}$ & $\mathrm{W}$ & 400 \\
\hline $\mathrm{m}$ & $0.0225 \mathrm{~kg}$ & $\gamma_{1}$ & 65 & $\mathrm{~g}_{\mathrm{a}}$ & 9.81 \\
\hline $\mathrm{R}$ & $10 \mathrm{ohms}$ & $\gamma_{2}$ & 1000 & & \\
\hline
\end{tabular}

Reference value of y is initially chosen as $0.01 \mathrm{~m}$ and it suddenly changes to $0.02 \mathrm{~m}$ after 0.02 seconds. Simulation results are obtained using MATLAB. 'Figure 6' shows that position reaches to the desired value in small finite time. 'Figure 7' show control current. It can be noted that the initial

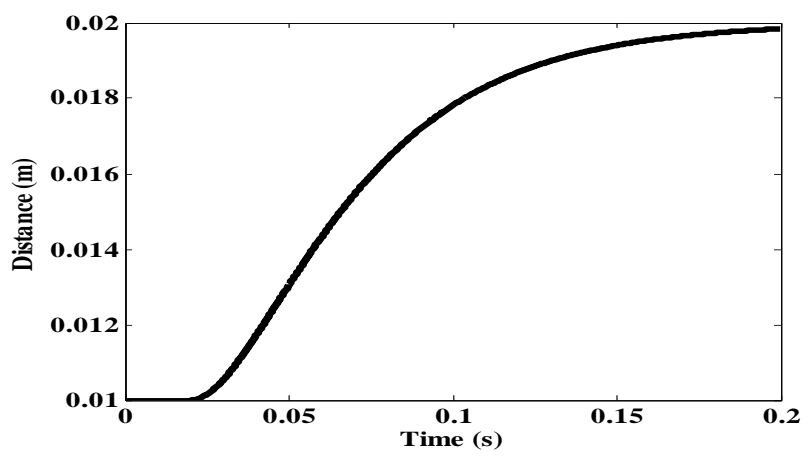

Figure 6 Distance versus Time

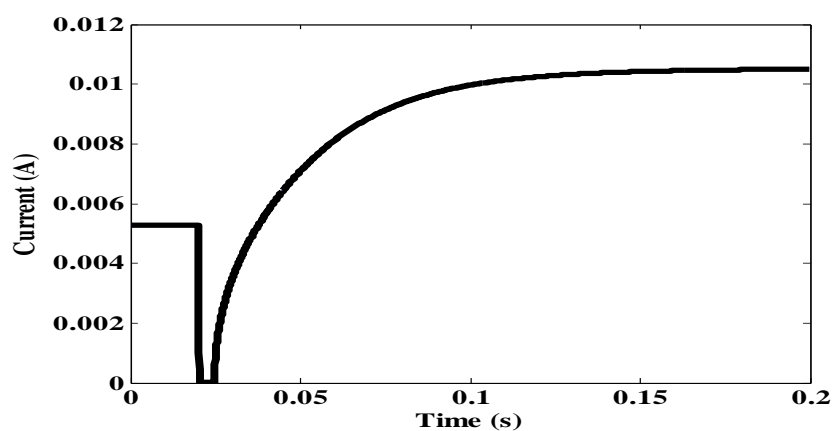

Figure 7 Current versus Time position of $y$ is nearer to the electromagnet than the final position. So when the object moves away from the magnet, the current initially decreases. But to maintain the object at the final position more current is needed and hence the current settles at a higher value. Slight disturbance in the current waveform is observed after the current settles to steady value. This is because the suspended object oscillates around the equilibrium position. Chattering is prominent in voltage waveform of 'Figure 8 '. Chattering which is the main drawback of sliding mode control is reduced by using saturation function or hysteresis function instead of signum.

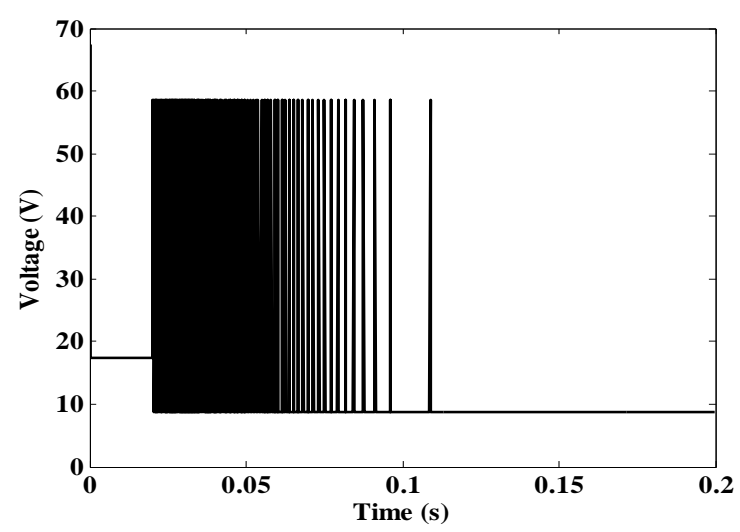

Figure 8 Voltage versus Time

\section{CONCLUSION}

In this paper the electromagnet and the optical sensors are modeled. Generally used screw based height gauge is replaced by travelling microscope to obtain more accurate results. As this scope is easily available in physics lab it considerably reduces the cost of the experimental set up. The actuator is modeled considering the non linearity between the force and current and current versus distance for stable position is plotted. A new polynomial expression is obtained for distance. Sensor modeling is done and range of sensing is increased by increasing the number of sensors. The design of sliding mode controller makes the system robust and independent of the uncertainties.

\section{REFERENCES}

[1]. Morita, T., Shimizu, K., Hasegawa, M., Oka, K., Higuchi, T., A Miniaturized Levitation System with Motion Control using a Piezoelectric Actuator, IEEE Trans. On Control Systems Tech., vol.10, no.5, p.666-670, 2002.

[2]. Lundberg, K. H., Lilienkamp, K. A., Marsden, G., LowCost Magnetic Levitation Project Kits, IEEE Control Magazine, oct.2004, p.65-69

[3].SungJun Joo and Jin H. Seo, 'Design and Analysis of the Non Linear Feedback Linearization Control for An Electromagnetic Suspension System`, IEEE Trans. on Control Systems Tech, vol.5, no 1, 1997. 
[4]. Jing-Chung Shen, 'Ho Control and Sliding Mode Control of Magnetic Levitation System ', Asian Journal of Control, vol.4 no 3, pp.333-340, 2002.

[5]. Sintayehu Challa, 'Magnetic Levitation on a Steel Ball, Thesis, Addis Ababa University 2007.

[6]. R. Sinha and M.L.Nagurka,`Analog and Lab view- Based Control of a Maglev System with Ni-Elvis`, Proceedings of IMECE 2005 ASME Int. Mechanical Engineering Congress and Exposition Orlando, Florida, USA 2005

[7]. Utkin. V, 'Variable Structure Systems With Sliding Mode, IEEE, TAC A.C., 1992.

[8]. Isidori, A. `Nonlinear Control Systems (New York: SpringerVerlag) 1989.

[9]. J. J. E Slotine and W. Li, 'Applied Nonlinear Control', Prentice-hall, Englewood Cliffs, $\mathrm{Nj}, 1991$.

[10]. Khalil H K, Nonlinear Systems, Printice Hall, 3rd Ed 2002.

[11]. Milica B. Naumovic, Boban R. Veselic,'Magnetic Levitation System in Control Engineering',Facta Universitatis, Series: Automatic control and robotics Vol. 7, no 12008.

[12]. B V Jayawant, 'Review Lecture on Electro- magnetic Suspension and Levitation Techniques'. Proceedings of R Soc Lond, vol A416, 1988.

[13]. Valer Dolga and Lia Dolga, 'Modeling and Simulation of Magnetic Levitation System' Annals of the Oradea University, Fascicle of Management and technology engineering, vol VI, 2007.
[14]. William G. Hurley and Werner H Wolfe, 'Electromagnetic Design of a Magnetic Suspension System, IEEE Trans. on Education, vol 40, no 2 May 1997.

[15]. Marjan Golob and Boris Tovomik, 'Modeling and Control of the Magnetic Suspension System' ISA transactions 42 2003.

\section{BIOGRAPHY:}

Mrunal Deshpande obtained her B.E (Electrical and Electronics Engineering from Nagpur University in 1992 and her M.E (Applied Electronics) from Anna University in 2005. She is pursuing her Ph.D programme .She has been in teaching field for more than 15 years. She has published 6 papers in the area of magnetic levitation. Her areas of interest include Non linear control systems, Electrical Machines and drives and Power Electronics. Currently, she is working as Assistant Professor in Department of EEE, SSN College of Engineering Chennai, Tamilnadu India

Dr B. L. Mathur obtained his B.E (Electrical Engineering) from University of Rajasthan in 1962 and his M.Tech. in Power Systems from IIT Bombay in 1964. He completed his Ph.D in 1979 from IISc Bangalore. His Ph.D thesis was adjudged as the best for application to industries in the year 1979 and won gold medal. He has been in teaching field for more than 45 years. He takes immense interest in designing electronic circuits. He has published 45 papers in National and International journals and 80 in National and International conferences. His area of interest includes Power Devices, Power Converters, Computer Architecture and FACTs. Currently he is working as Professor in Department of EEE SSN College of Engineering, Chennai, Tamilnadu, India. 